\title{
CREATING SUSTAINABLE BUSINESS: HOW DOES IT HAPPEN? \\ An Exploration of Motivators \& Facilitators in Three Organizational Settings in the U.S.
}

\author{
ROBIN T. BYERLY \\ Department of Management, Walker College of Business \\ Appalachian State University, Boone, North Carolina, U.S.A. \\ byerlyrt@appstate.edu
}

\begin{abstract}
Despite the fact that serious concerns regarding the deterioration of the environment and natural resources have been voiced for decades, current business and organizational approaches toward sustainability remain inadequate and substantially unsustainable. An important research question, therefore, has to do with understanding how to make positive behavior more prevalent in the face of many urgent global challenges. Newer business and organizational models that are significantly moving toward sustainability, for instance, serve as remarkable examples of such. What can we learn from them? This study seeks more specific answers to this broad question. How are modern organizations motivated to embrace sustainability initiatives in a genuine manner? How have they created their sustainable business models? How do they continue to sustain the initial momentum? What are the key factors that assist in the implementation of sustainability strategies? Lastly, how are they defining and achieving sustainability success? Answers to these questions were sought through an inductive and qualitative case research design that explored three quite different organizational settings, each pursuing sustainability objectives with advancing success and yet finding its own way in very different environments based on industrial, regulatory, and cultural influences. Nevertheless, several general characteristics seemed to accrue across organizational and industrial divides. A model for sustainability management, derived from the lessons learned in this study, is thus proposed.
\end{abstract}

\section{KEYWORDS}

sustainability management; leadership; motivators; facilitators 


\section{INTRODUCTION}

Scientists, environmentalists, economists, and legislators, among others, have for decades voiced serious concerns about the deterioration of the environment and natural resources. Despite this fact, however, business organizations and other institutions have been on a slow march in realigning long-term goals, strategies, cultures, and activities with more sustainable programs. It is evident that current approaches remain inadequate and substantially unsustainable even as the importance of sustainability is increasingly being recognized (Moritz-Rabson, 2019; Young, 2019). Many businesses and organizations still continue to operate with short-term economic objectives in mind, and government policies fail to motivate any adequately large-scale and continuous movement toward sustainability. Government and non-profit initiatives, therefore, cannot meet such challenges alone; all institutions and individuals must embrace these imperatives and alter their own behavior.

Understanding how to achieve more proactive behavior and build more innovative business models in organizations that are responsive to these concerns is an important research question, then, particularly in the face of many urgent sustainability challenges. Existing research and anecdotal evidence regarding how organizations, both large and small, are achieving this, however, is scant. This research study thus aims for answers in response to the broad question stated above, specifically to the following: How are modern organizations motivated to embrace sustainability initiatives in a genuine manner? How have they created their sustainable business models? How do they continue to sustain their initial momentum, and what are the key factors that assist in implementing sustainability strategies? Lastly, how are they defining and achieving sustainability success? Answers to these questions were sought through an inductive and qualitative case research design that explored three quite different organizational settings, each pursuing sustainability objectives with advancing success and yet finding its way in very different environments based on industrial, regulatory, and cultural influences. This method thus allowed for a comparison of theory and evidence based on three organizational case examples.

This paper is organized as follows. The issue of sustainability and its imperative is first discussed, followed by a review of the theory and literature on sustainability motivators and implementation of propositions developed. This is followed by 
methods and findings that inductively address both propositions and the larger research questions. A model is then developed using the lessons learned from case examples that are detailed with regard to their identifiable motivators, implementation facilitators, and observable sustainability outcomes. A summary following the general findings that seem to accrue across organizational and industrial divides concludes the study.

\section{SUSTAINABILITY IMPERATIVES FOR ORGANIZATIONS}

The United Nations, in seeking to respond to environmental and resource concerns and direct more sustainable development, established a special commission in 1983 that was later named the World Commission on Environment and Development (WCED, 1987). This was for the purpose of creating a report on the environment and the global problem up to the year 2000 and beyond, including proposed strategies for sustainable development. The Brundtland report (Our Common Future), as it came to be known, was published in 1987 and set the tone for the environmental summits that followed in Rio and Johannesburg. The report made it clear that sustainability needed to be understood as a multi-dimensional concept and that its management required a radical change in all aspects of organizational thinking, goals, strategy, planning, implementation, and values.

The overriding mission of this Commission was to demand that goals regarding economic and social development be defined in terms of sustainability. The UN thus adopted the term "sustainable development," which aims to "meet the needs and aspirations of the present without compromising the ability to meet those of the future." It pursued these objectives further through its Millennium Development Goals and does so now through its Sustainable Development Goals (SDGs), which are set for the year 2030 (United Nations General Assembly, 2015). Indeed, much progress has been made toward a number of sustainability objectives such as remedying poverty, addressing problems of population growth, improving sanitation, making safe water available, empowering women, and integrating environmental, social, and economic concerns in policy decisions between countries; to these may be added enormous growth in various fields of sustainability sciences and education at all levels as well as increasing movement toward energy conservation, renewables, and waste management. Many organizations have also signed on to the SDGs and declared intentions in favor of sustainability, although not always with successful 
action or implementation (International Portal for Sustainability Reporting, 2018). This begs the question, therefore, of why many organizations, despite a clear appetite for embracing the SDGs, still lack the strategy, tools, and culture needed to transform those commitments into tangible business actions.

\section{SUSTAINABILITY MOTIVATORS AND IMPLEMENTATION CHALLENGES}

The evolution of science, awareness, and consensual acceptance has provided a new sense of direction for all and inspires transformation for both individuals and corporations. Sustainable development cannot be realized without the contribution of business and institutional organizations (e.g., National Resources Defense Council, World Wildlife Fund, etc.), yet the extent of such involvement depends largely on their motivation. The sustainability-based view emphasizes organizational decision makers as managing a balance among concerns that is tied to a long-term planning horizon and that may emerge with some initial success and yet still falter later on. Evidence thus shows that some organizations struggle as their sustainability initiatives have serious implementation challenges such as maintaining continuity, overcoming difficult hurdles, attaining profitability, and motivating employees (Brockhaus, Fawcett, Knemeyer, \& Fawcett, 2017; Wilhelm, 2014).

\section{Sustainability Motivators}

Researchers suggest that primary motivators for sustainability include both extrinsic and intrinsic factors, with some arguing that one category is more persuasive than the other. Commonly accepted extrinsic motivations for corporate sustainability management as recorded in the literature include legitimacy, market success, and internal improvement (Bansal \& Roth, 2000; Epstein, 2008; Windolph, Harms, \& Schaltegger, 2014). Such motivations, while not necessarily moral or ethical in their derivation, are the most relevant nonetheless for businesses and other types of organizations. Companies want to be perceived as appropriate by societal stakeholders, perform well in their markets by appealing to consumers and investors, and improve operations and lower costs. The broad view here, with a clear motivation to improve an organization's bottom line and competitive position, may still be reflective, therefore, of a strategic response to changing circumstances, new corporate challenges, and adaptation for societal acceptance-smart business, in 
other words. These may be influenced realistically by industry setting and factors of competition; indeed, the drive to take on sustainability projects may well be in response to community pressures or regulatory oversight, motivated by the desire to improve image, build trust and reputation, and save money on costs (The Nielsen Company, 2018). Other drivers, moreover, include a new culture of environmentalism, new forms of financing and venture capital, sustainabilityfocused innovation, and the technology that enables it.

Although they remain a clear and persuasive motivator to some extent whenever present, regulatory pressures in the United States have remained typically capricious and non-pervasive and are not considered, by and large, to be a strong motivational factor as such across many industries and organizational settings (Howes et al., 2017). Indeed, existing market pressure motivates many institutions to reduce greenhouse gases and address social issues even without regulatory pressure. Many organizations, moreover, for-profit or otherwise, have signed on to other extrinsic motivations such as the UN Global Compact Principles, Caux Business Roundtable Principles, etc. The proliferation of environmental certifications is another extrinsic motivator as well, one designed to enhance image and present a positive presence to stakeholders.

There are those, however, who suggest that extrinsically oriented incentives have fundamental limitations, that they perhaps lack staying power or even the ability to either generate organizational wide support or inspire a new value system that will maintain a sustainability focus (van der Linden, 2015; van der Werff, Steg, \& Keizer, 2013). While modern society continues to place a high value on economic prosperity and much behavioral research emphasizes extrinsic incentives, particularly those with monetary benefits, Van der Linden (2015) argues that genuinely proenvironmental behavioral motivators are intrinsically oriented and result in physical and psychological rewards that are much more likely to be sustained over time. Others who uphold this general view (Gatersleben, Murtagh, \& Abrahamse, 2014; van der Werff et al., 2013), moreover, posit that pro-environmental behaviors are more likely to emanate from personal values and identities. Moral emotions, empathy and the ability to be compassionate, self-identity as caring, a desire to do the right thing - these traits are considered to be stable factors that transcend specific situations and influence planned behaviors that are enduring in themselves. If an individual describes herself or himself as an environmentally-friendly person, she/ he is likely to hold strong environmental values that are part of her/his identity, values that influence actions toward pro-environmental behavior. 
Self-identity as such appears to be a significant predictor of environmental sustainability behavior (Fielding, McDonald, \& Louis, 2008; Rimanoczy, 2014). Individuals who hold positive attitudes toward environmental activism think that there is normative support for that engagement and perceive that they can actually do something, thereby resulting in strong intentions on their part. This view may be expanded, furthermore, beyond the individual to understand the behavioral intentions of organizations that emphasize values and responsibility toward social issues, especially those that state a pro-environmental identity. Organizational learning must therefore play a role in building motivation across a spectrum of people and activities, particularly as identities are influenced by social interaction (Gatersleben et al., 2014). Social systems will embed and influence individuals as learning processes are incorporated into the generation of cooperative motivation for sustainable development (Hansmann, 2010; Windolph et al., 2014). Indeed, more and more attention has been given to the significant influence of spiritual, emotional, and shared values and meaning on both change leadership and leadership for innovation (Della Corte, Del Gaudio, Sepe, \& Zamparelli, 2017; Gill, 2002; Gehman \& Soublière, 2017; Rimanoczy, 2014).

That it appears to be essential for pro-environmental identity to be strongly embedded and understood organization-wide is inarguable. This in turn leads to the following propositions:

P1: Both intrinsic and extrinsic motivators will be highly associated with case examples.

P2: Intrinsic motivators will be more highly associated with case examples than will extrinsic motivators.

\section{Sustainability Implementation Challenges}

While pro-environmental behavior stems from a combination of motivational factors, its successful implementation and continuing endurance may depend on other enabling or facilitating influences. Making it stick requires continually navigating through obstacles, finding new opportunities, and a commitment that does not waver (Wilhelm, 2014). Implementation as such can prove to be difficult, even when environmental sustainability goals are increasingly embedded in planning stages. Sustainability initiatives at a minimum must be essentially reconciled with economic growth and return on investment, and while many organizations have 
seen economic benefits as cost savings are achieved, green-oriented customers increase, and employees are charged and motivated, this is not always an immediate outcome for some. Spangenberg (2004) argues that tradeoffs become riskier when sustainability programs engage both environmental and social objectives as one dimension may be overemphasized relative to another. Ongoing sustainability initiatives may suffer, therefore, if tangible returns diminish.

Innovation processes geared toward sustainable development, which may be key to improving operations in terms of eco-efficiency and cost reduction, might be difficult to engineer, however (Bos-Brouwers, 2010). Such improvements will necessarily be incremental and rely on continued focus and dedication, particularly as the ability to harness or create eco-innovations can be inhibited by bureaucratic rigidity, a high degree of formalization, or a focus on the short term or other organizational concerns (Bos-Brouwers, 2010). Regulatory overtures designed to incentivize sustainability initiatives can also be withdrawn, and tax credits and trade policies can all be changed, thereby impacting those institutions that have already taken action and made a commitment.

Other factors that influence successful implementation include criteria and measurement, leadership influence, stakeholder engagement, and early successes. The standard cliché "what gets measured gets managed" is true particularly when sustainability goals and their progress must be honestly measured and reported, communicated to stakeholders, and factored into subsequent efforts (Wilhelm, 2014). Carefully derived action criteria serve as important yardsticks for assessing the impact of policy proposals on sustainability objectives at various stages (Spangenberg, 2004).

The importance of leadership cannot be overstated given that organizational leaders must influence others through responsible decision-making, motivational communication, and by establishing the reality of sustainability through continuing initiatives (Gallagher, 2005). Leaders or "thinkers in action" are highly focused, committed and engaged, and inspiring and dedicated (Fullan, 2004). A supportive organizational culture must be created as well, and maintained alongside the adoption of a solid framework of environmental sustainability. Such efforts must involve stakeholders, including customers, communities, employees, and investors, as everyone needs to be brought into the sustainability agenda to ensure its continued success (Laurian \& Crawford, 2016). Moreover, while early triumphs provide fuel and motivation for new initiatives as well as promote stakeholder buy- 
in, implementation requires a time consideration for it to be successful. This means that multiple bottom lines must remain important for successive generations and performance must improve across all areas to create a sustainable advantage for the organization's future (Brockhaus et al., 2017).

Maintaining continuous and successful implementation thus poses challenges for organizations that seek a sustainability agenda. Overcoming such obstacles may involve multi-faceted influences and actions, with success broadly defined in terms of the continuity of the business model or successful navigation of implementation challenges. The extant literature as such leads to the following propositions:

P3: Eco-innovations will be highly associated with continuing success in sustainability implementation.

P4: Stakeholder engagement will be highly associated with continuing success in sustainability implementation.

P5: Strongly committed leadership will be highly associated with continuing success in sustainability implementation.

\section{RESEARCH METHODOLOGY}

An inductive case study research design allowed for a qualitative and comparative exploration of the research questions posed by three distinct organizational settings in the United States where sustainability objectives were pursued with advancing degrees of success, each finding its own way in very different environments affected by industrial, regulatory, and cultural influences. The method used in this study thus serves as a tool for analyzing and explaining critically the social reality of the phenomenon both holistically and retrospectively and for helping to attain an indepth understanding of causal processes. The three cases represented a renewable energy provider, an online network designed to generate contributions to renewable energy through carbon offsets, and a regional state university that has engaged with sustainability across its entire spectrum. Considered to be models of successful and continuing sustainability, these three organizations were explored through multiple interviews with the leaders and creators of $\mathrm{O} 2$ Energies and UCapture and with the Chief Sustainability Officer of Appalachian State University. Site visits were also 
conducted and triangulated with secondary anecdotal research on each of these organizations, thereby allowing for conclusions about their sustainability-focused business models to be inductively drawn.

The triangulation method in particular allowed for inferences regarding the factors that motivated these cases, how each organization managed to continue and overcome implementation challenges, and the outcomes they produced. The goal was to uncover rich explanatory variables that supported theory and proved generalizable across varied organizational settings. Conclusions regarding the propositions and broader research questions were thus drawn inductively through this process.

Another goal of this study was to determine factors that these cases might have in common and what lessons can be derived from them for a better understanding of how sustainable organizations can be created and made to endure over successive periods of time. A model was thus developed and proposed to provide insights on how organizations can successfully create and sustain more sustainability-focused strategies and successes.

\section{THREE ORGANIZATIONAL CASES}

This research focused on three organizational case studies from the United States: O2 Energies EMC, UCapture, and Appalachian State University. Brief descriptions of their innovative organizational approaches to sustainability are given in the paragraphs that follow. These examples were chosen because of their declared commitment to sustainability, uniqueness in terms of business model and industrial setting, and evidence of their growing success and accessibility. Their differences, however, must also be noted, such important similarities notwithstanding. A summary is provided in Table 1 .

\section{O2 Energies EMC}

Founded by Joel Olsen in 2009, O2 Energies EMC is an independent power producer that develops, owns, and operates solar farms across the southeastern United States. Sustainability is a core value in all aspects of O2's operations-the company is focused on developing and owning large-scale, ground-mounted solar 
power plants which are at present providing more than 100 megawatts of solar power through various energy utilities. O2's business model reflects a multifaceted approach to sustainability in that while the business purpose is to create and deliver renewable energy, many projects are developed to maximize local jobs and local investment while enhancing sustainability and educational opportunities in each project community.

\section{UCapture}

UCapture-Live Carbon Neutral is an online company dedicated to offsetting $\mathrm{CO}_{2}$. Founder and CEO Avery Michaelson touts a business model based on a looped value chain that connects companies (termed "partners") to online shoppers through UCapture technology. This generates commissions that ultimately go toward funding carbon offsets through renewable energy technology projects (UCapture, 2019). Thus, whenever customers shop online in connection with UCapture, the company's business partners pay commissions that go toward carbon offsetting projects. Using green-tech, therefore, allows the company to engage more people, motivate hundreds of online businesses to invest in a good cause, and generate funds to put toward sustainability initiatives. By using the UCapture app, online shoppers can connect again and again with participating retailers to keep their purchasing activities carbon neutral while firms that care for the environment build carbon offsetting credits. Company partners now exceed 25,000 to date, and include major online retailers such as Amazon, Marriott, Expedia, Walmart, and Microsoft, among others. Over 24,000 customers currently use the platform, with their continued participation bringing together and building relationships between companies and users.

\section{Appalachian State University}

A university institutional setting is the third organizational case. Located in the Blue Ridge Mountains of North Carolina, Appalachian State University (ASU) is a Pilot and Charter participant in the Sustainability Tracking, Assessment, \& Rating System ${ }^{\mathrm{TM}}$ (STARS), a transparent, self-reporting framework for colleges and universities to measure their sustainability performance with. ASU ranked first among institutions with master's programs and second overall in curriculum in the 2017 Sustainable Campus Index of the Association for Advancement of Sustainability in Higher Education (AASHE), which highlights top-performing colleges and universities according to various sustainability criteria (AASHE, n.d.). The university also tied 
for third with regard to buildings, a metric based on efficiencies in operations and maintenance, design and construction, and indoor air quality. Indeed, this university's journey toward sustainability has, over several years, permeated every aspect of its strategic mission, operations, buildings, educational programs, culture, and community.

\section{FINDINGS}

Much of what was learned about the sustainability motivation and implementation factors of these organizations matched and supported what has been proposed in the literature as well as all the propositions offered in this study. Furthermore, while the cases represent very different settings, many commonalities among them appear to be strongly evident and lead to some general conclusions.

How have these modern organizations been motivated to embrace sustainability initiatives in a genuine manner, and how have they created their sustainable business models?

While support for the relevance of both extrinsic and intrinsic motivators (Proposition 1) can be found in each case, the second proposition is also supported, that is, intrinsic motivators appear to be more persuasive than extrinsic ones in these organizations. For Joel Olsen, O2's founder, the initial motivator stems from his childhood (Olsen, 2017). He cites his mother, a climatologist and professor for the National Aeronautics and Space Administration (NASA) doing valuable work with the Reynolds Foundation, a non-profit program that has been dedicated to improving the quality of life for North Carolinians for over 80 years. Always driven to explore science, Olsen worked for some time making liquid crystal displays before he began exploring the idea of using that technology on rooftops without the need for an external power supply. Then, after completing his education, working at a number of jobs, and spending time in Scandinavia and Europe, he returned to the United States and found additional motivation for starting a sustainable business. The timeliness of other motivational factors coming together, moreover, also included the technology itself, which had improved enough to suggest that the time had come to begin his company in North Carolina. This, coupled with what appeared to be a long-term business opportunity, the powerful incentive of a renewable tax credit from the state, and a perceived market need, motivated him to begin a new venture. Decidedly influenced by intrinsic factors such as values, scientific curiosity, 
and an environmental identity, Osten was thus driven to pursue a career that would have positive social and environmental impact.

Headquartered and operating several solar farms in North Carolina, O2 is now expanding to neighboring states in a bid to broaden its market. Having grown over the years, it has moved away somewhat from partnering with large power firms to focus on building relationships with local electric cooperatives and municipal power companies. This new approach to working more directly with community cooperatives and utilities is aimed at increasing the economic and sustainability impact that $\mathrm{O} 2$ 's projects can have on the towns and counties they are located in.

When asked about his initial motivations for creating UCapture's unique business model, founder and CEO Avery Michaelson says that the idea goes way back to his childhood, as he has always been concerned about climate change and frustrated for years by its deniers (Michaelson, 2017). He learned about economics, carbon tax, and cap and trade while he was in college, and there made his first foray into seeking a market solution. It brought about a focus on consumption and negative externalities as well as the desire to devise a new approach that would assign the environmental cost to consumption. Eventually, he stumbled onto the engine for making it happen-affiliate marketing, a form of internet marketing in which a business rewards one or more affiliates for each visitor or customer brought to it by the affiliate's own marketing efforts. In this model, the affiliate puts the corporate partner's ad on its website. Then, when the participating online customer clicks to indicate carbon offsets, those transactions are tracked and UCapture gets a commission while the corporate partner gets a sale and credit for carbon offsets. The environmental shopping platform is connected and accessed through the UCapture app, and carbon offset projects like reforestation, methane capture, and renewable energies are all accounted for and reported on UCapture's website (UCapture, 2019).

For Michaelson, self-identity as one who valued the environment, the honing of innate skills (financial, marketing, technological), and the growing need for a solution relative to carbon output, coupled with his own personal belief that he could make a difference, all served as initial motivators.

Set in the Blue Ridge Mountains of northwestern North Carolina, Appalachian State University (ASU) is unique as a pioneer in university dedication to sustainability and a leader in the United States in holistically embracing such a mission. When 
asked about the motivations that propelled ASU to begin a program very few others were doing, Professor Lee F. Ball, Jr., who after spending several years in a supporting role took leadership of ASU's sustainability program as Chief Sustainability Officer, emphasized the identity of ASU (Ball, 2017). Simply stated, it is what ASU is and always has been. The environmental ethic has been there for decades, due somewhat to the institution's setting, geography, and culture.

A deeply embedded identity, purpose-focused mindset, and organizational values are all clearly reflected in both these business models and the motivation that drives them. The sustainability efforts of these organizations were not simply "added on"; whether by initial creation or through evolution, the examples in each case show a genuine and deep motivation driven by organizational values and identity. Intrinsic factors, which do matter largely and present prominently in each case, are matched by a variety of extrinsic factors; taken together, these serve to propel the sustainability initiatives studied herein.

How have these models of sustainability maintained their momentum, and what are the key factors that assist in the implementation of sustainability strategies?

A combination of several factors presents itself as significant for continued implementation success in each of these cases. Propositions 3, 4, and 5 thus appear to be well supported given that each case seems to have benefited profoundly from eco-innovations, stakeholder engagement, and committed leadership.

At O2 Energies, Olsen strongly emphasizes the need to build robust public relations with communities (leaders, citizens, and neighbors), investors, and legislators (Olsen, 2017). Considered a "solar evangelist" in the state (Downey, 2015), he is dedicated to the belief that clean energy should support the health and sustainability of local communities. Partnering with local organizations, therefore, helps to build this shared goal.

Olsen has also leveraged an in-depth understanding of state energy policy, existing energy infrastructure, project ownership, and tax structuring. $\mathrm{O} 2$, in striving for environmentally sensitive development, analyzes the impact of its solar farms on the surrounding environment with the aim of not impacting natural and cultural resources such as wetlands, habitats of endangered species, and archaeological sites. Equipment is less than twelve feet in height, and all its solar farms are enclosed by 
a seven-foot fence to ensure the safety of visitors, workers, and animals. What is promised in terms of sustainability to communities is thus honored. Indeed, one of the keys to the company's continued sustainability efforts is the business model itself, which has been modified, as mentioned above, to target local community power suppliers and broaden O2's market, particularly given that the North Carolina renewable tax credit expired at the end of 2015 and large power utilities like Duke Energy are moving in to take more control of the marketplace and exert influence on state policymakers (Keever, 2017).

Only over seven years in operation at this point, UCapture has grown exponentially in the short period of time since its founding. Several key factors have enabled that success. As Michaelson says, he did not create or invent anything; rather, he simply "connected" (Michaelson, 2017). Affiliate marketing and the Internet were already there, as was the existence of numerous carbon offsets. Browser extensions and mobile apps were improving. Thus, after trying to find out if anyone else was already doing it and finding none, he realized the profound need and decided to do it, although at first in a way that allowed him to continue with his existing finance job. He simply built a new business model out of what already existed, grabbing bits and pieces of technology and reconfiguring, slowly and without marketing, by building relationships. These included the many corporate partners who signed on to contribute as their purchasing customers specified such to be their preference; indeed, customers are also enjoined to participate based on these preferences.

Another enabling factor for successful growth and implementation has been a strategically designed approach through particular universities that also claim a sustainability agenda as declared in their mission statements. This works by engaging with them and communicating through and to students and faculty to spread the word and solicit more membership. The college market at present, moreover, represents the demographic with the most opportunity for engaging with online shoppers. New partnerships continue to spring up, including with Loyola University and Tello, thereby broadening the movement and purchasing scope for offsetting carbon. Tello, Sprint's new mobile virtual network operator, announced a new partnership with UCapture wherein it pledged to contribute the first monthly payments of its customers toward environmental projects that reduce greenhouse gas emissions, such as reforestation (PRWeb, 2017). Loyola University declared its intent to become carbon neutral and reduce the amount of carbon it uses in view of its ultimate goal of becoming a more sustainable campus; by teaming up with 
UCapture, its Evergreen Campus can now provide a free and easy program that helps each student to offset their own personal carbon footprint simply by shopping online with the UCapture app (Scheld, 2017).

In a succession of events at Appalachian State University, the strategic planning and creation of a sustainability council culminated in the institutionalization of sustainability and propelling of growth. The university understands how closely tied sustainability is to its mission and overarching objectives of cultivating knowledge, stimulating leadership, creating solution-oriented graduates, and embracing sustainability at the community and global level. Such a strong set of values has been a significant factor in keeping the sustainability momentum alive on campus. A hub for the leadership team that is supported by students, therefore, has been vital.

Support from local businesses and the community has also been critical for successful implementation since ASU's efforts must be viewed as authentic and not as greenwashing if everyone is to be enticed to get on board. The surrounding mountain community also provides uniqueness in that ASU is partnered with and supported by a number of socially-oriented and sustainable for-profit businesses whom the university engages with in multiple ways. Some of these entities, such as Appalachian Mountain Brewery (Appalachian Mountain Brewery, n.d.) and Bald Guy Brew (Bald Guy Brew, n.d.) as well as not-for-profits such as the F.A.R.M. Café (F.A.R.M. Café, n.d.) and Wine To Water (Wine To Water, n.d.), are proud to be part of a community-wide effort that defines not just an initiative but also a communitywide identity. Many local businesses, not-for-profits, entrepreneurs, and academics also come together frequently at events that sponsor the sharing of activities and information and work to keep everyone stimulated in the ongoing effort to make sustainability more firmly established across the mountain community. Examples of these events include the "Business for Good" annual meeting (Appalachian State University Walker College of Business, n.d.) and the Appalachian Energy Summit (Appalachian State University, 2018).

It thus appears that certain factors do facilitate and enable progress for organizational sustainability journeys that wish to stay on track. Most strongly observed, perhaps, was the significance of relationships built across traditional and newly defined spectrums that bring resources and ideas together. These include networking, using technology, forging new types of relationships, and building new business models for connecting partners and broadening sustainability initiatives 
and effects. The evidence shows that there are lessons that can be learned from strategic alliances, networks, emerging technologies, and information systems (Starik, Sharma, Egri, \& Bunch, 2005) as well as from communities and neighbors. We also see evidence suggesting that while these firms first embraced sustainability at a primary level, the outreach broadened over time, suggesting a natural evolution toward the United Nations' three-tiered mandate for sustainability as a multidimensional concept.

The combinations of factors that serve to facilitate successful and continuing sustainability initiatives admittedly vary and represent a somewhat unique synergistic effect for each case. Several characteristics, however, do appear to provide strong support for the propositions that eco-innovations, stakeholder engagement, and strongly committed leadership are highly associated with continuing success in sustainability implementation, at least in these case examples.

How are these organizations defining and achieving success in sustainability implementation?

Even though no propositions were developed for predicting sustainability success, it is interesting to note the varied types of positive outcomes experienced in these case examples as well as the many ways success was both claimed by company leaders and well supported by anecdotal evidence, despite success being assumed initially given the continuity of these companies. Success in sustainability implementation is clearly a multifaceted phenomenon.

With a focus on both social and environmental sustainability goals as suggested by the WCED, O2 Energy has been empowered by positive outcomes as it remains true to its identity. The generation of power from their solar farms-the company now produces over 200 megawatts of 100\% renewable and carbon-free solar energy (O2 EMC, 2015) - prevents the significant environmental degradation that would have occurred if the same amounts were generated by burning fossil fuels (O2 EMC, 2015). Harmful emissions are offset, no impermeable surfaces, smells, or noises are created, and their equipment can be removed after 30 years and the land returned to other uses. Moreover, as part of their commitment to make a positive impact on the community, the company also launched an educational initiative, working with K-12 public school systems and community colleges to increase knowledge and skills relevant to the industry. It also partners with organic farms to maintain 
solar installations using sheep, bees, and other sustainable farming practices, and provides employment by creating jobs in local areas, offering training and hands-on experience that lead to improved skill sets.

Successful outcomes for UCapture include a growing network relationship between firms and customers that fuels momentum toward greater carbon offsets and support for renewable energy. Companies had to be influenced to buy into this vision, however, e.g., getting on the right side of history, being socially responsible, and connecting with online customers in a meaningful way. The business model offers customers and companies something they cannot do on their own, for much more value is added when connected to the networked platform. Indeed, as many customers value companies that embrace sustainability in various ways, this model makes supporting those firms and taking personal responsibility in doing so easier and more doable. Offset projects include those directed at renewable energy, reforestation, and methane capture, and all are certified by third-party oversight. Over seven million kilograms of carbon have been offset so far, with more companies and customers joining every day (UCapture, 2019). UCapture is thus challenged to continue their operations and turn them into a profitable enterprise after providing support for carbon offset projects, as well as apply the model to all kinds of consumption. Organization goals include generating more partnerships with other online-supported models such Uber and OpenTable as well as with restaurants, events, and business-to-business solutions.

For Appalachian State University, Ball emphasized their outreach initiatives and administrative leadership as crucial for continuing success. He also touted good morale in the top team that guides organizational action (Ball, 2017). Students, too, are excited as service learning opportunities build hope and prove rewarding for them. ASU's Team Sunergy, for instance, dedicated itself in 2013 to building a car that would run on solar energy; today, undergraduate and graduate students from all backgrounds and majors research and work to build the next generation of solar vehicle. They have already competed internationally in the Formula Sun Grand Prix, winning third place in 2016 and second in 2017. Indeed, these are successes that match the stated university mission of educating and inspiring "doers," students who graduate and begin careers with a dedication to finding solutions.

ASU also has several certifications and memberships that maintain their focus on sustainability (e.g., LEEDS certification for buildings, AASHE Stars ratings, etc.) (Wall, 
2017). Outcomes also include a plethora of new educational programs across campus that involve both major and minor areas of study; all new construction and renovation projects dedicated to obtaining LEEDS certification; renewable energy projects on campus that involve solar, wind, and solar thermal resources; a movement toward zero waste through thoughtful purchasing, reduced consumption, and increased recycling and composting; a sustainability film series; the carbon neutral commuter program; green workplace certification; the annual Appalachian Energy Summit; and millions of dollars saved in utility costs (Appalachian State University, n.d.).

As emphasized by the Brundtland Report (WCED, 1987), the United Nations (United Nations General Assembly, 2015), and others, sustainability is holistic and multidimensional. Its pursuit is not just about energy reduction or a LEED-certified building; it is a philosophy of life, derived from values, principles, and respect for the complexity of life on this planet. For companies and organizations, then, the true pursuit of sustainability means integrating it into everything they do. All this springs from, and relates to, organizational values and identity.

\section{LESSONS LEARNED}

Lessons learned about sustainability motivators, implementation factors, and outcomes are summarized in Table 1. Motivators include a combination of extrinsic and intrinsic factors, and while evidence suggests that both are needed, theory and case examples support the notion that intrinsic motivators remain more persuasive and truly essential for successful implementation and continuation of sustainability initiatives. All of the case examples showed flexible navigation through implementation challenges, and each in its own way made good use of facilitating factors, the most significant of which was relationship building across many avenues. Outcomes are indeed multifaceted, and reflect not just the usual rewards but also an expansion of the initial sustainability energy into drawing others in and forging new paths. It is also worth noting that these three organizations exemplify a holistic approach to sustainability in multifaceted forms. While they differ in context and industry, all of them share several common attributes, most particularly identity and values, relationships and networking, the use of technology, new business models, and continued success through reinforcement. These commonly shared factors are 
also highlighted in Table 1, along with other factors that were either more specific to one organization or posited in the literature.

\section{Identity and Values}

The cases in this study show overwhelming support for the importance of selfidentity as an intrinsic motivator. Wilhelm (2014) argues that an organization must first define sustainability in a way that is both true to its identity and understood by all stakeholders. An environmental self-identity as such influences behavior that is consistent over time and motivates through a moral obligation that serves to promote collective action (Fielding et al., 2008; van der Werff et al., 2013). Each of these case examples reflects a deep set of values, strong sustainability identity and commitment, and a history that has served to embed these values over time. Continuity through challenges or setbacks is thereby driven by the entrenched values and sustainability identity that initially propelled the organization's journey. Indeed, while extrinsic motivators such as tax incentives (O2 Energies), economic savings (ASU), and technological opportunity (UCapture) do provide some additional influence, each of these organizations has been influenced the most, as is claimed and shown, by a strong sense of values and felt connection to the Earth. Leadership, too, is significant in each example as values and sustainability identity either began with company founders or were instigated by institutional leaders. These case examples, in bringing essential talents, know-how, and resources together, thus reflect an inspiration to search for better ways as well as a dedication to put that commitment into action.

\section{Relationships and Networking}

It is clear that the pursuit of sustainability is not a do-it-alone endeavor. Several researchers suggest that companies should focus on interdependencies between business and society and take collaborative approaches to sustainability initiatives (Loorbach, van Bakel, Whiteman, \& Rotmans, 2010; Svendsen \& Laberge, 2005) as many sustainability issues are much too complex and interconnected for individual firms to solve by themselves. Partnering with other companies through networking and relationship building can strengthen efforts through collaborative approaches that bring mutual benefit, provide access to new technologies, or tap into co-creative power. 


\begin{tabular}{|c|c|}
\hline EXTRINSIC MOTIVATION FACTORS & INTRINSIC MOTIVATION FACTORS \\
\hline $\begin{array}{l}\text { - Market pressure } \\
\text { - Negative externalities } \\
\text { (climate change) } \\
\text { - Sponsored incentives } \\
\text { (UN SDGs, certifications, etc.) } \\
\text { - Stakeholder concerns } \\
\text { (customers, employees) } \\
\text { - Availability of technology } \\
\text { - Timing }\end{array}$ & $\begin{array}{l}\text { Deeply embedded identity and } \\
\text { values } \\
\text { - Leadership that is passionate and } \\
\text { focused, self-assured, and purpose- } \\
\text { driven } \\
\text { - Other influential factors that } \\
\text { drive identity: family geography, } \\
\text { history, and culture } \\
\text { - Ability to combine relevant skills }\end{array}$ \\
\hline \multicolumn{2}{|c|}{ IMPLEMENTATION FACTORS } \\
\hline Facilitators & Challenges \\
\hline $\begin{array}{l}\text { - Relationships, networking } \\
\text { - New and reactive business models } \\
\text { - Small successes (reinforcement) } \\
\text { - Evolving technology } \\
\text { - Innovation in putting pieces and } \\
\text { partners together, making new/ } \\
\text { non-traditional partnerships, and } \\
\text { bridging the divide between for- } \\
\text { profits and non-profits, businesses, } \\
\text { and other institutions } \\
\text { - Leadership that is real and } \\
\text { continuing } \\
\text { - Social embeddedness-internal and } \\
\text { external } \\
\text { - Metrics-measure and report } \\
\text { everything } \\
\text { - Flexibility-readiness to alter or } \\
\text { change }\end{array}$ & $\begin{array}{l}\text { - Reconciling with growth and ROI } \\
\text { - Bureaucratic rigidity, formalization } \\
\text { - Short-term focus } \\
\text { - Changes in organizational } \\
\text { leadership and structure } \\
\text { - Changes in extrinsic factors (e.g., } \\
\text { tax incentives, etc.) } \\
\text { - Multiple bottom lines } \\
\text { - Timing and need for early success }\end{array}$ \\
\hline \multicolumn{2}{|c|}{ OUTCOMES } \\
\hline Intended & Other \\
\hline $\begin{array}{l}\text { - Achievement of sustainability } \\
\text { goals: carbon reduction, carbon } \\
\text { offsets, forest protection, } \\
\text { alternative energy, waste reduction, } \\
\text { educating and leading for the } \\
\text { future } \\
\text { - Business model and market success } \\
\text { - Profitability } \\
\text { - Endurance }\end{array}$ & $\begin{array}{l}\text { - Market goodwill } \\
\text { - Motivated employees } \\
\text { - Satisfied customers } \\
\text { - Community support } \\
\text { - Ongoing commitment and } \\
\text { actions-innovation that } \\
\text { produces new solutions/creations } \\
\text { - Lower costs } \\
\text { - New generation of passion and } \\
\text { purpose } \\
\text { - Expansion of sustainability fervor } \\
\text { and action }\end{array}$ \\
\hline
\end{tabular}

Table 1: Summary \& Lessons Learned: A Model for Creating Sustainable Organizations (commonly shared factors are emphasized; other factors included were either heavily specific to one organization or posited in the literature) 


\begin{tabular}{|l|c|c|c|}
\hline \multicolumn{1}{|c|}{ SIMILARITIES } & O2 EMC & UCapture & ASU \\
\hline $\begin{array}{l}\text { Holistic, dedicated, and with long-term } \\
\text { commitment to sustainability }\end{array}$ & $\checkmark$ & $\checkmark$ & $\checkmark$ \\
\hline $\begin{array}{l}\text { Visible evidence of leadership, purpose, and } \\
\text { cultural commitment }\end{array}$ & $\checkmark$ & $\checkmark$ & $\checkmark$ \\
\hline Clear evidence of sustainability achievement & $\checkmark$ & $\checkmark$ & $\checkmark$ \\
\hline $\begin{array}{l}\text { Continued planning and progress of } \\
\text { sustainability initiatives }\end{array}$ & $\checkmark$ & $\checkmark$ & $\checkmark$ \\
\hline $\begin{array}{l}\text { Suggested evidence of creative initiatives and } \\
\text { solutions, including technology }\end{array}$ & $\checkmark$ & $\checkmark$ & $\checkmark$ \\
\hline
\end{tabular}

\begin{tabular}{|c|c|c|c|}
\hline DIFFERENCES & O2 EMC & UCapture & ASU \\
\hline Industry setting & Power generation & Carbon offsets & Education \\
\hline $\begin{array}{c}\text { Size (revenue, } \\
\text { no. of } \\
\text { employees) }\end{array}$ & Medium & Small & Large \\
\hline $\begin{array}{l}\text { Organizational } \\
\text { purpose }\end{array}$ & $\begin{array}{l}\text { Provide solar } \\
\text { power, create jobs, } \\
\text { and empower } \\
\text { communities }\end{array}$ & $\begin{array}{l}\text { Offer opportunity } \\
\text { to businesses and } \\
\text { individuals to offset } \\
\text { carbon as well as } \\
\text { contribute to and } \\
\text { support carbon } \\
\text { offset projects }\end{array}$ & $\begin{array}{l}\text { Advance knowledge } \\
\text { through research } \\
\text { and scholarship, } \\
\text { and prepare } \\
\text { students to lead } \\
\text { purposeful lives } \\
\text { as engaged global } \\
\text { citizens who } \\
\text { understand their } \\
\text { responsibilities } \\
\text { in creating a } \\
\text { sustainable future } \\
\text { for all }\end{array}$ \\
\hline $\begin{array}{l}\text { History and } \\
\text { lifecycle }\end{array}$ & $\begin{array}{l}\text { Since } 2015 \text {, } \\
\text { growth focused } \\
\text { on geographical } \\
\text { expansion, power } \\
\text { production, and } \\
\text { networking; } \\
\text { now well- } \\
\text { established }\end{array}$ & $\begin{array}{l}\text { Began in } 2015 ; \\
\text { in } 2018 \text {, growth } \\
\text { focused on } \\
\text { increasing } \\
\text { membership \& } \\
\text { offsets; now well- } \\
\text { established with } \\
\text { a network of over } \\
25,000 \text { businesses } \\
\text { and over } 20,000 \\
\text { members }\end{array}$ & $\begin{array}{l}\text { Founded in } \\
1899 \text { and always } \\
\text { characterized by a } \\
\text { pioneering spirit; } \\
\text { growth focused on } \\
\text { student enrollment, } \\
\text { programs of } \\
\text { study, and the } \\
\text { advancement of } \\
\text { sustainability }\end{array}$ \\
\hline $\begin{array}{c}\text { Use or } \\
\text { application of } \\
\text { technology }\end{array}$ & $\begin{array}{l}\text { Solar power } \\
\text { plants }\end{array}$ & $\begin{array}{l}\text { Online } \\
\text { development for } \\
\text { affiliate marketing }\end{array}$ & $\begin{array}{l}\text { Renewable energy, } \\
\text { LEEDS construction }\end{array}$ \\
\hline
\end{tabular}

Table 2: Organizational Case Example Similarities and Differences 
Relationship building is overwhelmingly evident and significant in the three case settings described above. O2 Energies, for instance, focuses on the communities where it places its solar farms, integrating the establishment and operation of its projects with local energy providers, city and state legislators, financiers, neighbors, and farms, among others. Believing that clean energy should support the sustainability and health of the community, the company partners with reputable organizations that share the same goal of improving the local natural and social environment. Its solar farms provide opportunities for farmers to raise sustainable, grass-fed beef, and their educational initiative to increase knowledge of renewable energy technology in cooperation with K-12 public school systems and community colleges remains to be a positive local impact in each community it serves. Indeed, O2's continuing search for better technology and new solar farm opportunities constantly brings new partners into its sphere of work.

UCapture CEO Michaelson built a business model that relies wholly on relationships between firms, customers, universities, and renewable energy projects that are constantly growing in every dimension. The same emphasis can be seen in the example of Appalachian State University with its network of partners that includes campus departments, faculty, students, community businesses and nonprofits, events, social justice initiatives, and the larger sphere of sustainability enablers (e.g., AASHE, Green Building Council, etc.). In each case, a continually growing network of relationships serves as an essential element for success in sustainabilityoriented actions, identity embeddedness, and keeping the journey alive.

\section{Technology}

Moving toward becoming more sustainable means finding more efficient methods, building better products, and creating cleaner processes, all of which present technological challenges. Key success factors include basic knowledge and skills, an understanding of regulation and the ability to lobby, a well-organized approach to managing and planning costs (Olsen, 2017), a customized set of technology tools that are tailor-made for the company's needs, and a system of review, checkpoints, and roadmaps (Michaelson, 2017; Petala, Wever, Dutilh, \& Brezet, 2010). Technological understanding and inherent skill must, at the most basic level, attenuate the effort required for sustainability-oriented actions and solutions. While technological resources can certainly be acquired, each of the firms studied here began with leaders and organizational support that possessed the scientific 
and technological acumen necessary for sparking the desire to build something. This, combined with an environmental identity, led to the natural emergence of a sustainability-focused momentum.

Building and maintaining a sustainability-focused agenda also requires technological innovation, and potentially across multiple organizational dimensions. Joel Olsen (Olsen, 2017) cites O2's constant search for better construction materials in a bid to reduce the possible environmental impact of solar farms on surrounding areas, whether these be in the height of solar panels or their required rotation. Michaelson's sustainability journey with UCapture has been an incremental search for technological solutions through electronic connections that are constantly being reconfigured. Appalachian State's emphasis on technological progress is evident in building construction and improvements, energy use on campus, the handling of food and non-food waste, their interdisciplinary programs of study, the Team Sunergy initiative, and the Energy Summit, among others. Indeed, Ball declares that ASU's sustainability initiatives have forward progress and simply cannot stop (Ball, 2017).

\section{New Business Models}

Since the business case for sustainability requires the integration of societal and environmental matters into the core business of the firm or institution, challenges present themselves if organizations are not compensated for reducing negative externalities and/or creating positive ones. Lüdeke-Freund (2010) posits the notion that innovative business models can approach value creation in radically new ways as well as combine with sustainability-oriented business opportunities in eco-innovation by bridging technological innovations, improving organizational aspects, and finding new market positions. The overarching idea is to create value in ways that bring about both private and public benefits; indeed, the case examples described herein exemplify eco-innovative business model creation or modification with this fundamental goal in mind.

The example of $\mathrm{O} 2$ Energies is that of a business model in flux. Originally created to take advantage of regulatory incentives in the state of North Carolina and distribute energy through partnerships with large and established public utilities, it has recently been altered in response to changing state regulations, a more competitive positioning of public utilities, new financial and societal opportunities as municipalities move toward independent energy provision, and the company's 
dedicated mission of bringing value to communities. The UCapture business model, on the other hand, is unique in that it was created to seize opportunities available in networking, affiliate marketing, and internet applications for bringing people together in the marketplace in new ways to serve eco-interests. As for Appalachian State University, it has been a pioneer in blending the old with the new to create a university-wide institutional model in sustainability, gradually providing all areas of campus infrastructure, activities, and educational programs with a new focus and form. All these case examples as such indicate that the business model and its management are significant factors in steering the design, implementation, change, and control of an organization's efforts in creating and securing competitive advantage while at the same time serving the sustainability-oriented mission.

\section{Successes and Reinforcement}

One must admit, given the many obstacles that may diminish enthusiasm, stall efforts, and impede organization-wide support and buy-in, that sustainability endeavors are often challenged both to get started and to continue. A prominent takeaway from these case examples, therefore, is the realization that much of successfully continuing organizational commitment actually springs from earlier successes that get celebrated and built upon. This reinforces the notion that sustainability is indeed possible, that organizational actors and actions can truly make a difference. Indeed, many businesses often begin logically with the "low hanging fruit" or easy, doable actions like making the switch to low-energy lightbulbs, reducing wasted standby power and water, improving recycling facilities in the workplace, moving to eco-friendly cleaning products, replacing outdated appliances and electronic equipment, installing motion sensors for lighting, going paperless, and/or reducing business travel (Corbett, 2015). These are all great first steps to take, yet they may not reflect a holistic approach and should not be the end goal when it comes to sustainability improvements. They do, however, offer initial successes and create stepping-stones to greater things if properly couched in the organization's mission, structure, leadership, and culture. 


\section{CONCLUSION}

The movement toward sustainability has not evolved much despite the more than 30 years since the publication of the Brundtland Report. Yet while progress toward a truly sustainable world has been altogether slow, organizations focused on sustainability can still be created and sustained as evidenced in these three organizational case examples. To borrow from an old African proverb which states that it takes a village to raise a child, the evidence suggests that it also takes a village (or community) to move us toward new behavior and a life focused on sustainability. Indeed, it is striking to note that a multiplicity and coordination of players ultimately enabled the organizations in each of these cases to achieve their sustainability objectives. Characterized by dedicated leadership with strong environmental identities, technological acumen, and the ability to influence others, each organizational approach stayed true to the United Nations' sustainable development objectives by being holistic and all-encompassing in its values and efforts to create meaningful outcomes both internally and externally.

Hargreaves and Fink (2006) maintain that for sustainability to succeed it must matter and endure, that it must spread, not cause harm, and honor the past while creating the future. These sustainability principles are matched in substance by the organizational sustainability characteristics outlined above. While each case example in this study represents different contexts and industries, one can still observe attributes common among them that appear to motivate and facilitate toward sustainability success. Indeed, lessons learned from these case examples support the following traits as essential for moving toward this goal: an environmental identity and holistic approach accompanied by a strongly embedded set of values and a clear objective of creating positive social and environmental impact; an appreciation and reverence for others and community with a focus on embracing and building lasting, mutually beneficial relationships; a willingness to explore new technologies and build upon innate resources and knowledge; an eco-innovative approach to creating and modifying business models that are uniquely designed to connect providers with customers and generate benefits for all; and dedication to a continued focus on organizational sustainability and the ability to use successes to fuel that forward movement. 


\section{REFERENCES}

AASHE [Association for the Advancement of Sustainability in Higher Education].

n.d. About us. Available at http://www.aashe.org/about (accessed July 20, 2019).

Appalachian Mountain Brewery. n.d. Home page. Available at http://amb.beer/.

Appalachian State University. n.d. About sustainability at Appalachian. Available at http://www.sustain.appstate.edu/about (accessed July 15, 2019).

Appalachian State University. 2018. Appalachian Energy Summit. Available at https:// sustain.appstate.edu/initiatives/energy-summit/2018/ (accessed July 15, 2019).

Appalachian State University Walker College of Business. n.d. Business for good. Available at http://www.business.appstate.edu/b4g (accessed July 15, 2019).

Bald Guy Brew. n.d. Home page. Available at http://www.baldguybrew.com.

Ball, L. 2017. Personal communication, December 7.

Bansal, P., \& Roth, K. 2000. Why companies go green: A model of ecological responsiveness. Academy of Management Journal, 43(4): 717-736.

Bos-Brouwers, H. E. J. 2010. Corporate sustainability and innovation in SMEs: Evidence of themes and activities in practice. Business Strategy and the Environment, 19(7): 417-435.

Brockhaus, S., Fawcett, S. E., Knemeyer, A. M., \& Fawcett, A. M. 2017. Motivations for environmental and social consciousness: Reevaluating the sustainability-based view. Journal of Cleaner Production, 143: 933-947.

Corbett, H. 2015. 4 ways business can go beyond the low-hanging fruit of sustainability. GreenBiz, March 13. Available at https://www.greenbiz.com/ article/4-ways-go-beyond-low-hanging-fruit-sustainability (accessed September 10, 2019).

Della Corte, V., Del Gaudio, G., Sepe, F., \& Zamparelli, G. 2017. The role and implications of values-based leadership. Journal of Organisational Transformation \& Social Change, 14(3): 187-213. 
Downey, J. 2015. O2 Energies gets new partner, new focus. Charlotte Business Journal, February 4.

Epstein, M. J. 2008. Making sustainability work: Best practices in managing and measuring corporate social, environmental, and economic impacts. Sheffield, UK: Greenleaf.

F.A.R.M. Café. n.d. Home page. Available at http://www.farmcafe.org/index.html (accessed September 10, 2019).

Fielding, K. S., McDonald, R., \& Louis, W. R. 2008. Theory of planned behaviour, identity and intentions to engage in environmental activism. Journal of Environmental Psychology, 28(4): 318-326.

Fullan, M. 2004. Leadership and sustainability: System thinkers in action. Thousand Oaks, CA: Corwin Press.

Gallagher, D. R. 2005. Building environmental management systems focused on sustainability: The influence of employees, company leaders and external stakeholders. In M. Starik, S. Sharma, C. Egri, \& R. Bunch (Eds.), New horizons in research on sustainable organisations: Emerging ideas, approaches and tools for practitioners and researchers: 60-79. Sheffield, UK: Greenleaf.

Gatersleben, B., Murtagh, N., \& Abrahamse, W. 2014. Values, identity and proenvironmental behaviour. Contemporary Social Science, 9(4): 374-392.

Gehman, J., \& Soublière, J. F. 2017. Cultural entrepreneurship: From making culture to cultural making. Innovation: Organization \& Management, 19(1): 61-73.

Gill, R. 2002. Change management-or change leadership? Journal of Change Management, 3(4): 307-318.

Hansmann, R. 2010. "Sustainability learning": An introduction to the concept and its motivational aspects. Sustainability, 2(9): 2873-2897.

Hargreaves, A., \& Fink, D. 2006. Sustainable leadership. San Francisco: John Wiley \& Sons. 
Howes, M., Wortley, L., Potts, R., Dedekorkut-Howes, A., Serrao-Neumann, S., Davidson, J., Smith, T., \& Nunn, P. 2017. Environmental sustainability: A case of policy implementation failure? Sustainability, 9(2): 165-181.

International Portal for Sustainability Reporting. 2018. Businesses fail to report sustainable development goals (SDGs). Available at https://www.sustainabilityreports.com/businesses-fail-to-report-sustainable-development-goals-sdgs/ (accessed July 20, 2019).

Keever, E. 2017. Solar boom creates tension between utilities, developers in North Carolina. Charlotte Talks with Mike Collins, May 3.

Laurian, L., \& Crawford, J. 2016. Organizational factors of environmental sustainability implementation: An empirical analysis of US cities and counties. Journal of Environmental Policy \& Planning, 18(4): 482-506.

Loorbach, D., van Bakel, J. C, Whiteman, G., \& Rotmans, J. 2010. Business strategies for transitions towards sustainable systems. Business Strategy and the Environment, 19(2): 133-146.

Lüdeke-Freund, F. 2010. Towards a conceptual framework of business models for sustainability. In R. Wever, J. Quist, A. Tukker, J. Woudstra, F. Boons, \& N. Beute (Eds.), Knowledge collaboration \& learning for sustainable innovation: 28 pages. ERSCP-EMSU Conference 2010 (October 25-29). The Netherlands. Available at https://papers.ssrn.com/sol3/papers.cfm?abstract_id=2189922 (posted December 16, 2012).

Michaelson, A. 2017. Telephone interview, October 25.

Moritz-Rabson, D. 2019. What is greenwashing? Businesses pledge climate change actions-sometimes to cover up unsustainable practices. Newsweek, Sept. 30. Available at https://www.newsweek.com/what greenwashing-businesses-pledgeclimate-change-actionssometimes-cover-unsustainable-1462168 (accessed February 14, 2020).

O2 EMC. 2015. About O2 emc. Available at http://www.o2emc.com/about-o2-emc (accessed July 20, 2019). 
Olsen, J. 2017. Telephone interview, December 4.

Petala, E., Wever, R., Dutilh, C., \& Brezet, H. 2010. The role of new product development briefs in implementing sustainability: A case study. Journal of Engineering and Technology Management, 27(3-4): 172-182.

PRWeb. 2017. Tello teams up with UCapture to reduce the carbon footprint. Available at http://www.prweb.com/releases/2017/08/prweb14561671.htm (accessed October 15, 2019).

Rimanoczy, I. 2014. A matter of being: Developing sustainability-minded leaders. Journal of Management for Global Sustainability, 2(1): 95-122.

Scheld, M. 2017. Loyola plans on reducing carbon footprint with UCapture. The Greyhound, October 17. Available at https://thegreyhound.org/site/2017/10/17/ loyola-plans-on-reducing-carbon-footprint-with-ucapture/ (accessed September 10, 2019).

Spangenberg, J. H. 2004. Reconciling sustainability and growth: Criteria, indicators, policies. Sustainable Development, 12(2): 74-86.

Starik, M., Sharma, S., Egri, C., \& Bunch, R. 2005. Introduction: Emerging ideas, approaches and tools for practitioners and researchers. In M. Starik, S. Sharma, C. Egri, \& R. Bunch (Eds.), New horizons in research on sustainable organisations: Emerging ideas, approaches and tools for practitioners and researchers: 10-17. Sheffield, UK: Greenleaf.

Svendsen, A. C., \& Laberge, M. 2005. Convening stakeholder networks: A new way of thinking, being and engaging. Journal of Corporate Citizenship, 19: 91-104.

The Nielsen Company. 2018. The evolution of the sustainability mindset. Available at https://www.nielsen.com/us/en/insights/report/2018/the-education-of-thesustainable-mindset/ (accessed February 15, 2020).

UCapture. 2019. About page. Available at http://www.ucapture.com/about (accessed February 15, 2020). 
United Nations General Assembly. 2015. Transforming our world: The 2030 agenda for sustainable development. Available at http://www.refworld.org/ docid/57b6e3e44.html (accessed October 10, 2019).

van der Linden, S. 2015. Intrinsic motivation and pro-environmental behaviour. Nature Climate Change, 5: 612-613.

van der Werff, E., Steg, L., \& Keizer, K. 2013. It is a moral issue: The relationship between environmental self-identity, obligation-based intrinsic motivation and pro-environmental behaviour. Global Environmental Change, 23(5): 1258-1265.

Wall, E. 2017. Appalachian earns no. 1 ranking from AASHE for sustainability among master's institutions. Appalachian Today, November 15. Available at https:// today.appstate.edu/2017/11/15/aashe (accessed September 15, 2019).

WCED [World Commission on Environment and Development]. 1987. Our common future. Oxford, UK: Oxford University Press.

Wilhelm, K. 2014. Making sustainability stick: The blueprint for successful implementation. Upper Saddle River, NJ: Pearson Education Inc.

Windolph, S. E., Harms, D., \& Schaltegger, S. 2014. Motivations for corporate sustainability management: Contrasting survey results and implementation. Corporate Social Responsibility and Environmental Management, 21(5): 272-285.

Wine To Water. n.d. Home page. Available at https://www.winetowater.org/ (accessed September 15, 2019).

Young, A. 2019. Coca-Cola, Pepsi highlight the 20 corporations producing the most ocean pollution. USA Today, June 17. Available at https://www.usatoday. com/story/money/2019/06/17/20-corporations-behind-the- most-oceanpollution/39552009/ (accessed February 14, 2020). 
Robin T. Byerly is a professor of Management at Appalachian State University in Boone, North Carolina, U.S.A. Her research interests include sustainability, business ethics, corporate citizenship and responsibility, evolving trends, and the intersection of social issues with business. She received her Ph.D. in Strategic Management from Florida State University in 1995 and has published in the Academy of Management Journal; Managerial and Decision Economics; Social Business; Journal of Leadership, Accountability, and Ethics; and Business \& Professional Ethics Journal, among others. She is also the author of several book chapters. 